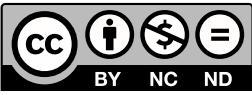

Estudos Teológicos foi licenciado com uma Licença Creative Commons Atribuição - NãoComercial - SemDerivados 3.0 Não Adaptada

http://dx.doi.org/10.22351/etv59i2.3486

\title{
A ANTROPOGÊNESE ENTRE A TEOLOGIA E A ONTOLOGIA: DisPOSITIVO ONTOLÓGICO E FORMA-DE-VIDA ${ }^{1}$
}

\author{
The Anthropogenesis between Theology and Ontology: \\ Ontological dispositive and form-of-life
}

\section{Marcus Vinicius de Souza Nunes ${ }^{2}$ \\ Vicente Artuso ${ }^{3}$}

\begin{abstract}
Resumo: Os escritos do filósofo Giorgio Agamben dialogam com as mais diversas áreas do conhecimento e, dentro do campo filosófico, com as mais diversas escolas. Neste trabalho apresentamos um ponto de articulação entre a obra de Agamben e de Hegel a partir da noção de antropogênese, o processo de engendramento dos conceitos de humano e de vida na ontologia e teologia ocidentais. A compreensão daquilo que Agamben chama "dispositivo ontológico" nos leva ao redimensionamento do papel do pensador, filósofo ou teólogo na sociedade contemporânea. A ontologia, a teologia, a práxis e a política formam no Ocidente um único feixe de relações que cabe ser desarticulado para liberar-nos para uma nova forma-de-vida.
\end{abstract}

Palavras-chave: Ontologia. Dispositivo. Antropogênese. Forma-de-vida.

Abstract: The writings of the philosopher Giorgio Agamben dialogue with many areas of knowledge and, within the philosophical field, with many schools. In this paper, we present a point of articulation between the work of Agamben and that of Hegel from the notion of anthropogenesis, the process of engendering the concepts of human and life in the Western ontology and theology. The understanding of what Agamben calls an "ontological dispositive" leads us to re-dimension the role of the thinker, philosopher or theologian, in contemporary society. The ontology, the theology, the praxis, and the politics, generate in the West of a single beam of relations that must be disjointed to free ourselves into a new form-of-life.

Keywords: Ontology. Dispositive. Anthropogenesis. Form-of-life.

1 O artigo foi recebido em 20 de outubro de 2018 e aprovado em 14 de junho de 2019 com base nas avaliações dos pareceristas ad hoc.

2 Mestre.Studium Theologicum. Curitiba, PR. E-mail: mvinicius.snunes@gmail.com

3 Doutor. Pontifícia Universidade Católica do Paraná, Curitiba, PR. E-mail: vicenteartuso@gmail.com 


\section{Introdução}

Nosso trabalho pretende apresentar a íntima vinculação que há entre o pensamento de Hegel e o de Agamben. Deste sabemos a ligação, em especial, com a obra de Heidegger e de Foucault, do qual continuam as problemáticas, ainda que em outro registro. De Heidegger, Agamben toma a questão da história do ser, mas enquanto constituição de um dispositivo ontológico, isto é, enquanto pensa a cisão entre ser e potência, que constitui a máquina linguística e política ocidental. De Foucault, a genealogia das tecnologias de poder e a arqueologia dos saberes, o que faz do trabalho agambeniano uma arque-genealogia. No que tange à filosofia de Hegel, Agamben parece situar-se no campo da arqueologia da ontologia, enquanto pensamento onto-lógico, pensamento da coisa enquanto dita na linguagem e da linguagem enquanto diz a coisa.

Para Agamben ${ }^{4}$, Hegel teria percebido, na dialética da Certeza Sensível, que o desenvolvimento da ontologia se deu sobre um processo de antropogênese que lhe é correspondente, que como onto-logia só funciona como linguagem que pré-supõe o não humano no humano: "Por que o humano só pode encontrar-se pressupondo o não-verdadeiramente-humano, e a ação política livre e a obra do homem só excluindo - e ao mesmo tempo incluindo - o uso do corpo e a inoperosidade do escravo?"5.

Queremos indicar como e por que Agamben reconhece em Hegel a revelação dessa pressuposição na linguagem. Trata-se de perceber, na obra de Agamben, o quanto a situação política dos corpos, matáveis ou não, entregues à destruição ou preservados, enraíza-se em um problema ontológico já apontado por Hegel. Parece-nos indubitável que o aprofundamento dessa questão pode lançar novas luzes sobre a compreensão da obra de ambos e, ao mesmo tempo, oferecer elementos teóricos para pensarmos a filosofia e a política contemporâneas sob nova ótica. Entretanto, falar a obra de Hegel, ou a obra de Agamben é propor um esforço demasiado hercúleo e, talvez, irrealizável. Por isso nossa leitura se centra nos seguintes pontos.

Primeiro, apresentar a noção de dis-positivo onto-lógico ${ }^{6}$ em Agamben a partir de Hegel. Para isso é necessário apresentar os Escritos Teológicos da Juventude, textos do chamado "jovem Hegel”, compilados e publicados em 1907 por H. Nohl, e que tiveram importante impacto na recepção da obra hegeliana após sua publicação. Também é indispensável metermo-nos à leitura da Fenomenologia do Espírito, na medida em que para Agamben é na dialética da Certeza Sensível que se reconhece uma grande contribuição de Hegel à questão.

\footnotetext{
AGAMBEN, Giorgio. $O$ uso dos corpos: Homo sacer IV, 2. São Paulo: Boitempo, $2017 \mathrm{~b}$.

AGAMBEN, Giorgio. A potência do pensamento: Ensaios e conferências. Belo Horizonte: Autêntica, 2017a. p. 67.

6 Dis-positivo onto-lógico aparece assim grafado sempre que queremos referir-nos não apenas ao conceito agambeniano, mas à proximidade etimológica de dis-positivo com os correspondentes germânicos Ge-stell (usado por Heidegger) e Gestalt (usado por Hegel). É um dis-pôr, um pôr-para, um pôr-junto. Onto-lógico, por sua vez, quer manter presente a ambiguidade entre o ente (ontos) e a linguagem (logos) que marcam o pensamento ocidental. Mais que um preciosismo, a precisão que fazemos tem uma função didática.
} 
De Agamben, o eixo de análise se baseia em $O$ uso dos corpos, Homo Sacer $I V, 2$, que finaliza a série Homo Sacer e que é como uma summa agambeniana, que resume todas as suas mais importantes questões. Daí procedemos à indicação dos elementos mínimos para análise do dispositivo ontológico e da forma-de-vida. Para esta, ainda acrescentamos a leitura de Altíssima Pobreza, Regras monásticas e forma de vida. ${ }^{7}$ Isso fazemos porque após a análise de como o dis-positivo onto-lógico é desarticulado a partir da forma-de-vida, queremos, seguindo uma tipologia entre àquelas agambeniana e hegeliana, descer ao nível do paradigma na sua concretude histórica. Sem dúvida, dada a densidade da obra de ambos, será necessário o recurso a diferentes textos (principalmente no que se refere a Agamben) para situarmos a problemática em um contexto mais amplo.

\section{Dispositivo onto-lógico e teologia hegeliana}

O primeiro ponto de nossa pesquisa é o desenvolvimento da noção de dispositivo ontológico, ou, como viemos destacando aqui, dis-positivo onto-lógico. Uma mais recente elaboração desse conceito se encontra em $O$ uso dos corpos. Homo Sacer VI, 2, último livro lançado da série Homo Sacer. Na primeira parte do livro, partindo da noção de homem sem obra ruma à definição do grego chresis, uso, e as consequências nos modos do relacionamento que temos com o corpo como si e outro (o corpo do escravo tornado outro no uso do senhor). Na segunda parte $O$ uso dos corpos desenvolveu uma arqueologia da ontologia. A noção de dispositivo ontológico aparece nessa segunda parte como o modo de Agamben compreender o fato marcante da história do pensamento, que tem grandes consequências para o Ocidente: para a política, direito, religião, arte, ciência. Esse evento fundamental é a cisão entre ato e potência, ou dito em termos quase idealistas, entre ser-em-si e pôr-em-obra, reconhecida e descrita a partir da obra de Aristóteles.

Antes de adentrarmos essa cisão e sua ligação à obra de Hegel, é preciso esclarecer o primeiro termo desse binômio (ou talvez trinômio, ou ainda quatrinômio), que é o dis-positivo onto-lógico. O texto mais conciso, e ao mesmo tempo fundamental, dessa discussão terminológica em Agamben é $O$ que é um dispositivo? ${ }^{8}$. Ali afirma que "as questões terminológicas são importantes em filosofia" ". E questão terminológica, em filosofia, confunde-se (para bem ou para mal) com uma filologia moderada, uma história dos termos em seu desenvolvimento. Quanto ao termo dispositivo, Agamben parece admiti-lo, primeiramente, em sentido foucaultiano: um conjunto heterogêneo de instituições que inclui elementos linguísticos e não linguísticos, sempre usados em

7 AGAMBEN, Giorgio. Altíssima pobreza: Regras monásticas e forma de vida [Homo Sacer, IV, 1].São Paulo: Boitempo, 2014.

8 AGAMBEN, Giorgio. O que é um dispositivo? Outra travessia, Florianópolis: UFSC, n. 5, 2005. Disponível em: $<$ https://periodicos.ufsc.br/index.php/Outra/article/view/12576/11743>. Acesso em: 01 mar. 2018.

9 AGAMBEN, 2005, p. 9. 
uma função estratégica dentro de certas relações de poder formando um tipo de rede generalizada que legitima ou deslegitima saberes e práticas. ${ }^{10}$

Esse termo foucaultiano seria formado a partir de duas fontes. Uma, hegeliana, mediada por Jean Hyppolite, e outra de origem heideggeriana. Essa seria principalmente ligada ao conceito de Ge-stell, com o sentido de técnica, de aparato (Gerät). É etimologicamente equivalente ao latim dispositio. Não pode ser desprezada a "parte heideggeriana" do uso do termo, mas aqui centramo-nos nos elementos da filosofia hegeliana.

Hyppolite em Introdução à filosofia da história de Hegel ${ }^{11}$ faz a apresentação da filosofia do jovem Hegel, como é chamado o período da escrita dos Theologische Jungendschriften, os Escritos Teológicos da Juventude ${ }^{12}$. Nesses textos, entre os quais se encontram Religião Popular e Cristianismo e A positividade da religião cristã, aparece o termo Positivität, positividade, desde a oposição entre religião natural e religião positiva, estendendo-se a todo o âmbito de conflito entre natureza e história. Mas, como termo ambíguo, positividade também referir-se-ia à instância de reconciliação entre natureza e história no pensamento. Isso ficou conhecido no romantismo como Filosofia da Reconciliação (Philosophie der Versöhnung).

Agamben procura fazer uma breve história do termo dispositivo no seu principal âmbito de desenvolvimento: o teológico. Dispositio foi o termo latino preferido pelos padres do Ocidente para a tradução do grego oikonomía. Esse conceito, profundamente estudado por Agamben em $O$ Reino e a Glória, foi a saída teológica do Oriente para pensar o problema de uma cisão em Deus entre ser e agir, entre sua natureza e o modo de sua ação no mundo. Assim, quando se referia a Deus em si, ou como ficou conhecida, à teologia das processões, falava-se simplesmente de teologia, enquanto para referir-se à ação de Deus no mundo criado usava-se o termo oikonomia .

A Positivität hegeliana, tal qual aparece nos textos da juventude, tem essa densidade teológica (repitamos, são textos chamados teológicos). E toda essa densidade com origem na oikonomia e na teologia trinitária, na filosofia de Hegel e na de Heidegger (que não é nosso intuito explanar) sobrevive, arqueologicamente, no instrumental teórico foucaultiano que Agamben assume. Entretanto, o resultado a que Agamben chega em $O$ que é um dispositivo? sobre a filosofia hegeliana é que:

${ }^{10}$ CASTRO, Edgardo. Introdução a Giorgio Agamben: Uma arqueologia da potência. Belo Horizonte: Autêntica, 2012.

${ }^{11}$ HYPPOLITE, Jean. Introdução à filosofia da história de Hegel. Rio de Janeiro: Elfos; Lisboa: Edições 70, 1995.

${ }^{12}$ A constituição do texto dos Theologische Jungendschriften é por si mesma uma questão intrincada. O texto recebido por Hyppolite, por Kojève, por Lukacs, por Marcuse, por Foucault, é o que foi compilado por H. Nohl em 1907. Na Gesammelte Werk de Hegel, publicada em Hamburg por Felix Meiner, se encontra sua versão crítica. Nós, contudo, optamos pela edição de Nohl e isso por uma razão muito simples. O que nos interessa não é tanto descer ao nível da crítica redacional, mas o quanto pode ser percebido a partir da obra que foi recebida. Junto com a edição alemã de Nohl, utilizamos a edição italiana Scritti Teologici Giovanili, traduzida por N. Vaccaro e E. Mirri e publicada em Nápoles pela Guida Editori em 1977. Além de constituir uma excelente tradução em língua romana, possui excelente aparato crítico composto de notas, notas introdutórias e comentários. 
Se "positividade" é o nome que, segundo Hyppolite, o jovem Hegel dá ao elemento histórico, com toda a sua carga de regras, ritos e instituições impostas aos indivíduos por um poder externo, mas que se torna, por assim dizer, interiorizada nos sistemas das crenças e dos sentimentos, então Foucault, tomando emprestado este termo (que se tornará mais tarde "dispositivo"), toma posição em relação a um problema decisivo, que é também seu problema mais próprio: a relação entre os indivíduos como seres viventes e o elemento histórico, entendendo com este termo a conjunto das instituições, dos processos de subjetivação e das regras em que se concretizam as relações de poder. $\mathrm{O}$ objetivo último de Foucault não é, porém, como em Hegel, aquele de reconciliar os dois elementos. E nem mesmo o de enfatizar a conflito entre estes. Trata-se para ele antes de investigar os modos concretos em que as positividades (ou os dispositivos) atuam nas relações, nos mecanismos e nos "jogos" de poder"

Nossa questão com relação à interpretação agambeniana é de ultrapassar o limite que ela nos impõe. Não obstante o tema da reconciliação estar presente no jovem Hegel, não cremos poder ler a positividade a partir do resultado da filosofia hegeliana (o que seria um procedimento hegeliano). É necessário descer à profundidade desse conceito, mediante o qual se pode reconstituir o modo pelo qual Hegel analisa a Modernidade (noção caríssima ao seu pensamento) a partir da ambiguidade fundamental das positividades que apresenta, a saber, a teologia cristã, a arte, o direito. Descer à ambiguidade fundamental é reconhecer a máquina bipolar que opera a separação entre vida sensitiva e vida intelectiva (forma em que se expressa o problema da cisão na Modernidade), vida animal e homem, como o fundamento e motor da história.

O fato é que com toda a evidência os dispositivos não são um acidente no qual os homens caíram por acaso, mas eles têm a sua raiz no mesmo processo de "hominização" que tornou "humanos" os animais que classificamos sob a rubrica homo sapiens. ${ }^{14}$

Esse processo de hominização, de antropogênese, Hegel lê à luz da separação entre razão e sentimento, entre moral e vida ${ }^{15}$, entre religião positiva e religião natural ${ }^{16}$. É nessas "máquinas bipolares" hegelianas que podemos encontrar, em ligação com sua história teológica, um elemento de crítica ao dis-positivo onto-lógico. Ademais, outro aspecto que, ao que nos parece, não foi suficientemente aclarado por Agamben e que não é de somenos para compreendermos a constituição de tal dis-positivo é um conceito não descurável na Fenomenologia do Espírito ${ }^{17}$ : a noção de Figura. Figuras são as determinações históricas que o Espírito, ou a Ideia, ou o Saber Absoluto, assume. O termo alemão usado na Fenomenologia é justamente Gestalt, que compõe o mesmo campo semântico de Ge-stell e que poder-se-ia ler, em chave

\footnotetext{
13 AGAMBEN, 2005, p. 11.

14 AGAMBEN, 2005, p. 13.

15 HEGEL, Georg Wilhelm Friedrich. Scritti teologici giovanili. Guida Editori, 1977. p. 33.

16 HEGEL, 1977, p. 28.

17 A Fenomenologia constitui um ponto de inflexão no pensamento hegeliano. A rigor, pode ser considerado o último texto da juventude e é a porta de entrada para o sistema.
} 
quase teológica, o que é dis-posto pelo Espírito de si mesmo. Vemos, por aqui, o quão profícua pode ser a precisa compreensão do desenvolvimento do conceito de positividade em Hegel, como arqueologia da ontologia.

\section{Linguagem pressuponente}

Só conseguimos apreender a efetividade do dispositivo a partir de seu caráter onto-lógico. Com isso se explica nossa insistência em cunhar a expressão separando as duas raízes. O dis-positivo onto-lógico, como já sublinhamos, trata dessa cisão fundamental que ocorre na história do pensamento ocidental e que chegará ao seu paroxismo na filosofia hegeliana da cisão subjetiva que só é superada na reconciliação com o Absoluto.

Quaisquer que sejam os termos em que a divisão se articula no decurso da história (essência primeira/essência segunda, existência/essência, quod est/quid est, anitas/quidditas, natureza comum/suposto, Dass sein/Was sein, ser/ente) o decisivo é que, na tradição da filosofia ocidental, o ser, assim como a vida, sempre será interrogado com base na cisão que o atravessa. ${ }^{18}$

Agamben reporta-se às Categorias de Aristóteles e faz a seguinte constatação: apesar de ser o texto por excelência de lógica no corpus aristotelicus, há ali a formulação de muitas teses em ontologia. E a razão disso é formalmente simples, ainda que de difícil elucidação quanto ao seu alcance, a saber, que Aristóteles trata "dos entes enquanto significados pela linguagem e da linguagem enquanto se refere às coisas"19. Ontologia e lógica vivem em uma ambiguidade constante, que é constituinte da filosofia, ao ponto que "as categorias serão apresentadas tanto como gêneros da predicação quanto como gêneros do ser"20.

Essa relação está longe de ser explícita ao longo da história da filosofia. Ao contrário, uma arqueologia da ontologia só pode ser articulada a partir da tarefa da desarticulação do onto-lógico, para percebermos o vazio operado no meio dessa máquina. O caráter não tematizado do onto-lógico é o que Agamben chama linguagem pressuponente. É a linguagem enquanto pré-supõe, põe como um su-posto (hypokeimenon) uma coisa nomeada que escapa à linguagem. Su-põe-se a coisa nomeada como não-linguística. Articula-se assim uma máquina na qual o fundamento não pode ser objeto de crítica, já que funda. É sobre essa pressuposição que se estabelece a ambiguidade entre ser e linguagem, ontologia e lógica. Para Agamben, é tarefa do pensamento reconduzir o pressuposto à linguagem para tornar inoperante o dis-positivo. Mas de que forma isso é possível? Em que campo isso se dá?

A separação entre o dizer e aquilo-sobre-o-que-se-diz é o modo pelo qual o dis-positivo é posto em movimento. Retomando a dialética da certeza sensível na

\footnotetext{
18 AGAMBEN, 2017b, p. 139.

19 AGAMBEN, 2017a, p. 140.

20 AGAMBEN, 2017b, p. 141.
} 
Fenomenologia, Agamben reconhece o desvelar do "caráter pressuponente da linguagem"21. Quando simplesmente perguntamos "aqui! Qual aqui?", "agora! Qual agora?", de repente a imediatez da linguagem na sua pressuposição sobre o que se diz passa a ser mediada pela história. O desvelamento do pressuposto põe à luz, junto com a linguagem, a própria antropogênese. No dispositivo onto-lógico se repete o próprio processo da antropogênese, o processo que nos faz entes de linguagem, entes que enunciam.

O que está em questão no dispositivo, assim como em toda sua nova declinação histórica, é a articulação entre linguagem e mundo, que a antropogênese abriu como "história" para os seres da espécie Homo Sapiens. ${ }^{22}$

Mas com que alcance isso poderia ser compreendido em Hegel? Para Agamben, Hegel consegue pôr em evidência a pressuposição linguística. Mas poderíamos dizer que ao pô-la em evidência teria conseguido desarticular o poder de captura do dis-positivo? Ao recordarmos que a sua filosofia é filosofia do Espírito, parece-nos razoável dizer que nela o indivíduo é capturado no interior de uma máquina ainda mais totalizante, isto é, capturado no próprio Espírito.

O singular deve também percorrer os degraus-de-formação-cultural do espírito universal, conforme seu conteúdo; porém, como figuras já depositadas pelo espírito, como plataformas de um caminho já preparado e aplainado. ${ }^{23}$

Por outro lado, podemos tomar o caminho da Fenomenologia como a reversão da pressuposição linguística até chegarmos ao pressuposto último. Aliás, o próprio Agamben nos faz atentar para uma importante precisão terminológica hegeliana. Ao tratar no epílogo de $O$ uso dos corpos de uma potência destituinte, a potência que desarticula os dispositivos, lerá essa destituição que é um tornar inoperante a partir do verbo grego usado na Carta aos Romanos por Paulo: katargein. Ora, segundo ele, não passou despercebida a Hegel a tradução que Lutero faz por aufheben, um superar que é um guardar. ${ }^{24} \mathrm{~A}$ Fenomenologia é justamente, em todo o seu caminho, o tornar inoperante conservando: um dis-positivo (Gestalt) é conservado na sua desativação. Temos de nos haver com o fato que o sistema da Fenomenologia, como sistema que é, termina numa conciliação última, o absolute Wissen. Mas esse não é uma Gestalt no mesmo sentido das anteriores, um dis-positivo, mas aquele que dispõe, enquanto o que põe para si mesmo o seu con-figurar.

Todo esse processo, que, sim, culmina em uma conciliação, é permeado de negatividade. Agamben percebe-o e o apresenta em A linguagem e a Morte, um seminário

\footnotetext{
21 AGAMBEN, 2017a, p. 152.

${ }^{22}$ AGAMBEN, 2017a, p. 153.

${ }^{23}$ HEGEL, Georg Wilhelm Friedrich. Fenomenologia do Espírito. Petrópolis: Vozes; Bragança Paulista: Editora Universitária São Francisco, 2008. p. 41.

24 AGAMBEN, 2017b, p. 132.
} 
sobre o lugar da negatividade ${ }^{25}$. A negatividade em Hegel como o processo de reconhecimento da inefetividade da linguagem em capturar o indizível, ou, o que é pré-suposto como não dito toda vez em que a linguagem, como o mais universal, diz: "Nós denominamos um universal um tal Simples que é por meio da negação" ${ }^{26}$. Esse nós hegeliano é justamente o filósofo quando assume a potência desveladora do pensamento.

Na própria medida que o indizível foi, até certo ponto, para o jovem Hegel, um problema vital, o modo pelo qual ele, no posterior desenvolvimento de seu pensamento, elucidou o seu mistério torna-se ainda mais significativo e deveria ser objeto de uma consideração problemática. ${ }^{27}$

Tal problematização Agamben realiza em A linguagem e a morte e, de certa maneira, em $O$ uso dos corpos. Levá-la à frente no sentido de determinar o alcance do desvelamento da linguagem pressuponente enquanto dis-positivo onto-lógico é de inegável importância para compreender como se gestou no Ocidente um dispositivo biopolítico que captura a vida em seu interior. A antropogênese pensada a partir de Hegel nos Escritos Teológicos e na dialética da Certeza Sensível na Fenomenologia nos permitiria desarticular a articulação entre linguagem e vida, que redunda em prejuízo para o vivente, na medida em que a linguagem se constitui como conjunto de relações objetivas de poder que con-formam a vida a partir de sua cisão.

\section{Forma de vida}

Uma das questões centrais da obra de Agamben é a articulação entre vida e vida nua, entre bíos e zoé, isto é, o dispositivo biopolítico. Aparece de forma premente em Homo Sacer, o poder soberano e a vida nua I e constitui o cerne de toda a série Homo Sacer. Aparece também em diversos outros textos seus, como em Meios sem fim, notas sobre a política, que funciona como uma série de apontamentos sobre o sentido técnicos de alguns termos usados por Agamben.

O sintagma vida nua, uma mera vida biológica, foi a grande criação da máquina biopolítica no Ocidente. Que se possa reconhecer a existência de uma dinâmica biológica na vida do homem é inegável. Mas a máquina biopolítica pressupõe que não apenas se possa reconhecer, mas se possa isolar algo como uma mera vida, para fora do fato político, para fora da linguagem. Como captar esse não captável que se encontra excluído do discurso? Ora, não se pode. É o discurso mesmo que produz a nudez dessa vida. É um fato de linguagem a criação de um espaço não linguístico que toma a palavra ao ser humano.

O que significa essa tomada de palavra? Esse silêncio produzido migra os corpos do campo das possibilidades para o dos fatos brutos. Uma vida nua, uma vida bio-

25 AGAMBEN, Giorgio. A linguagem e a morte: Um seminário sobre o lugar da negatividade. Belo horizonte: UFMG, 2006.

26 HEGEL, 2008, p. 87.

27 AGAMBEN, 2006, p. 23. 
lógica capturada no interior da máquina biopolítica, é a vida condenada ao determinismo de sua condição factual. Ora, nesse determinismo não é mais possível política em sentido pleno, isto é, como práxis autêntica em que o ser falante do que fala é posto em questão no próprio discurso, o ser agente do que age posto em questão na ação mesma. O império do direito que captura a vida no seu interior é o fim da ação política. O que constitui o paradigma da soberania é o determinismo da natureza biológica produzido no interior do dispositivo jurídico. Esse é o determinismo do direito que se mantém sobre a conservação de seu poder de vida e de morte. ${ }^{28}$

Mas o que significa essa consciência sempre presente de sermos constantemente ameaçados pela morte soberanamente exercida? Segundo Agamben, a vida nua, isto é, a vida separada de sua forma na máquina biopolítica, sempre foi o fundamento oculto da soberania. O estado-de-exceção tornado paradigma biopolítico da contemporaneidade é o explicitar-se do que se encontrava oculto na soberania. É o estado-de-exceção, não como possibilidade iminente, mas como a norma da soberania, em que a lei decide pela sua própria supressão, que nos põe de frente com o risco de morte que corremos

Temos de ficar alertas, entretanto, para o perigo que representa a mera menção de uma separação, de uma oposição, entre vida e morte. A vida biológica, segundo Agamben, "forma secularizada de vida nua ${ }^{29 "}$, não é, por si mesma, nenhum indicativo preciso para a nossa discussão. Ao contrário, a sacralidade da vida biológica oposta à morte biológica é também linguisticamente e politicamente produzida, e é sobre essa produção que se articula o paradigma biopolítico. Não se trata, então, de produzir uma forma de vida que se oponha à condenação à morte que diariamente sofremos. As coisas são mais complicadas que isso. Trata-se mais de compreender o funcionamento e desativar um dispositivo que separa a vida da sua forma, articulando-a numa oposição vida-morte que dá sustentação ao exercício do poder. Fazer da vida biológica um laboratório experimental e defender a sacralidade, a intocabilidade da vida, situam-se dentro do mesmo marco paradigmático. ${ }^{30}$

O sintagma forma-de-vida se refere à superação dessa cisão. A uma vida que escapa a toda soberania, a uma política feita fora da política, uma vida que é inseparável de sua própria forma. Mas como se faz concretamente isso? Aí nós encontramos mais uma sofisticação da reflexão de Agamben. Uma resposta imediata nos apontaria certo tipo de militância, o exercício de uma tarefa, uma missão histórica. O filósofo italiano faz opção por uma resposta mais complexa, como complexo é o paradigma da soberania que produz a vida nua. Essa superação passa por um experimentum do pensamento. Pensamento não é aqui a mera atividade psíquica. Pensamento é um evento do pensar que redescobre a potência do viver em cada vida singular. Trata-se então não de uma forma universalmente determinada da vida, mas de uma "vida que

\footnotetext{
${ }^{28}$ AGAMBEN, 2017b, p. 15.

${ }^{29}$ AGAMBEN, 2015, p. 43.

${ }^{30}$ AGAMBEN, 2015, p. 18.
} 
gera sua forma no próprio viver" ${ }^{\prime 1}$. Nesse experimentum é impossível separar a vida da sua forma.

O experimentum do pensamento é, sobretudo, um experimentum de comunicação. Em Agamben, pensamento e comunidade se identificam. A potência do pensamento só pode ser potência na comunidade, onde nem tudo é ato, porque a comunidade não é possível a partir da participação em um comum em ato, mas é possível pela participação na própria comunicabilidade. "Podemos nos comunicar com os outros só através daquilo que em nós, assim como nos outros, permaneceu em potência." 32

É necessário articular dois momentos do próprio experimentum de Agamben em que a revelação da pressuposição linguística do dis-positivo onto-lógico aparece como forma-de-vida, comunidade sem pressupostos. A primeira parte, a mais "teorética", é desenvolvida em $O$ uso dos corpos. Nessa obra, sobretudo, é preciso ressaltar o vínculo determinante entre antropogênese, arqueologia e forma-de-vida.

Temos de compreender porque o projeto agambeniano redundou em uma arqueologia. Não é um método exterior, por assim dizer, à coisa mesma. Forma-de-vida e arqueologia se interpenetram. Uma forma-de-vida, uma vida inseparável de sua forma, é aquela que põe em questão sua própria antropogênese, seu processo de hominização. Um processo se coloca fora das preocupações de sentido da metafísica tradicional. Nessa, há a preocupação em torno de um mistério: como podem coincidir, no homem, vida e língua? Pressupõem-se uma língua "sobrenatural”. A metafísica repete o mito do deus que ensina o homem a falar, que dá a linguagem ao homem. $\mathrm{Na}$ arqueologia a pergunta é pelo homem que se dá na linguagem, isto é, a pergunta de como pôde ocorrer uma cisão entre vida e língua, de que forma uma máquina política, ou melhor, biopolítica, engendra essa cisão. É uma pergunta que enquanto mostra o dis-positivo onto-lógico tem a possibilidade de desativá-lo.

Sendo assim, trata-se, antes de tudo, de neutralizar o dispositivo bipolar zoé/bíos. Como acontece todas as vezes que nos encontramos frente a uma máquina dupla, aqui é preciso precaver-nos tanto da tentação de jogar um polo contra outro quanto daquela de contrair simplesmente um no outro em nova articulação. Trata-se, pois, de tornar inoperosos tanto o bíos quanto a zoé, para que a forma-de-vida possa aparecer como o tertium que se tornará pensável unicamente a partir dessa inoperosidade, a partir desse coincidir - ou seja, cair juntos - de bios e zoé. ${ }^{33}$

\section{Paradigma: regras monásticas e novitas franciscana}

O segundo momento está na análise de um paradigma, isto é, de um modelo histórico de forma-de-vida para Agamben. Trata-se da relação entre as regras monásticas e a vida que faz em Altíssima Pobreza, em especial da consideração que faz do movimento franciscano.

\footnotetext{
${ }^{31}$ AGAMBEN, 2017a, p. 247.

${ }^{32}$ AGAMBEN, 2017a, p. 19.

${ }^{33}$ AGAMBEN, 2017b, p. 252.
} 
A grande diferença do movimento franciscano, como a principal ordem mendicante no início do século XII e que faz dele, historicamente, uma anomalia dentro do direito é sua autocompreensão como novitas. Essa novidade seria o próprio descobrimento da vida. A vida já aparecia na tradição monástica anterior, mas em outro sentido. Regula vitae é vida normatizada por um direito. Os cenóbios e os mosteiros não desconheciam uma forma de vida, entretanto essa era tecnicamente regulada. $\mathrm{O}$ exercício de uma askeseis, o empreendimento de uma tecnologia sobre a vida mesma que busca aproximá-la de um modelo extrinsecamente posto. Estamos, aqui, dentro do paradigma clássico do direito, onde norma e ação são como dois espaços completamente distintos, mas articulados entre si gerando um vazio sempre pressuposto, jamais tematizado. ${ }^{34}$ Mas é nesse vazio mesmo que o movimento franciscano vai operar. Os movimentos, em geral, representam uma mudança radical em relação ao paradigma monástico anterior. Tanto as ordens mendicantes, que permanecem fiéis ao centro de poder romano, quanto os tantos outros movimentos pauperísticos que foram considerados heréticos, são novitas em sentido amplo.

Estava em jogo nos movimentos não a regra, mas vida, não o fato de poder professar este ou aquele artigo de fé, mas de poder viver de maneira determinada, praticando alegre e abertamente uma determinada forma de vida. ${ }^{35}$

A regra, na tradição monástica, é, em sentido foucaultiano, uma prática de veridicção. É um esforço de articular a vida com um discurso sob o qual a própria vida cai, sob o qual é declinada. Produzir a verdade, dizer a verdade, como prática religiosa, é uma constante preocupação com uma ortodoxia a qual a regra faz aspirar. A regra é um suspiro pelo orthés, para produzir em si o verdadeiro. Nos movimentos do século XII não é mais a veridicção a questão, mas o viver uma vida, vivere vitam sancti Evangelii. Este retorno ao Evangelho como forma vivendi é comum a todas essas expressões.

O que diferencia o franciscanismo é uma consciência mais elaborada a respeito dessa novitas. Não só se apresenta como novitas, como a compreende a partir do sintagma forma vitae. É só no franciscanismo que forma vitae se torna um "termo técnico" "36. Mas o que é forma no sintagma franciscano? Forma é paradigma, exemplo, modelo: "Forma vitae designa, nesse sentido, um modo de vida que, ao aderir estritamente a uma forma ou modelo, de que não pode ser separado, se constitui por isso mesmo como exemplo" "37. É curioso o fato que Agamben não tenha ressaltado

\footnotetext{
${ }^{34} \mathrm{Na}$ vida monástica já se pode ler uma indeterminação entre norma e vida, já que a vida se faz norma. $\mathrm{O}$ paradigma de ação não é uma norma jurídica, mas a vida do fundador, dos santos, do evangelho. Sua tese vê no franciscanismo a radicalidade da novitas que extrapolou os limites do direito vigente. Mas, parece-nos, não é apenas a autoproclamação da novitas que o distingue do monasticismo anterior. As regras monásticas não teriam sido açambarcadas pelo direito? Uma leitura da Regula Benedicti e da Regula Fratrum Minorum lado a lado nos pode revelar a diferença.

35 AGAMBEN, 2014, p. 99.

${ }_{36}$ AGAMBEN, 2014, p. 100.

37 AGAMBEN, 2014, p. 101.
} 
aqui a importância do termo aderir, adherire, termo que aparece diversas vezes nas Fontes Franciscanas e que constitui uma chave de acesso indispensável para a autocompreensão do movimento franciscano. ${ }^{38}$

É necessário atentarmos ao alcance do movimento franciscano como paradigma daquela comunidade, daquele experimentum que desativa o dis-positivo onto-lógico enquanto faz coincidir vida e vida nua fora do direito. No movimento franciscano, a norma cede lugar à performatividade e a interpretação, fundada na cisão ontológica da filosofia ocidental, é substituída pela exposição, ou, o pôr-a-partir-de-si-mesmo. Se Agamben está correto ao afirmar que "a exposição é o lugar da política"39, queremos ver o alcance disso ao analisar uma regula vitae que só pode ser exposta e nunca comentada. ${ }^{40}$

\section{Considerações finais}

Podemos perceber que pensar o dis-positivo onto-lógico e pensar a forma-de-vida é um único experimentum em Agamben. É mister notar que tanto ele como Hegel perceberam o entrelaçamento do direito e da política em uma comum origem religiosa. ${ }^{41}$ Tanto um como outro encontram na análise de paradigmas religiosos a desarticulação da pressuposição linguística. Em Agamben é o paradigma Homo Sacer e a forma-de-vida. Em Hegel, a religião cristã pensada em sua positividade histórica. Dois paradigmas antropogenéticos.

Não podemos, todavia, supor que Agamben uso o termo dis-positivo em sentido hegeliano. Tampouco podemos deixar de notar a proximidade entre as duas concepções. Em um e outro está patente que não se pode proceder uma análise das instituições fora do paradigma onto-linguístico que domina o Ocidente. Ser é ser dito na linguagem. A pretensão naturalista e determinista que se erigiu em padrão de cientificidade na realidade corresponde a um paradigma de dominação. A afirmação da pura vida, da vida nua, como ente fora da linguagem, é um factoide usado na dominação dos corpos.

Nossa tese pode parecer árida, mas é profícua. Reconhecer em ambos o paradigma da antropogênese é encontrar os meios de realizar um experimento de linguagem que é, por isso mesmo, experimento político que desarticula a aparente obviedade do pensamento ocidental: o que é esse homem sobre o qual falamos? Que vida é essa que conforma a nossa linguagem, mas que a consideramos fora da linguagem? É necessário sair do homem como sujeito já constituído biopoliticamente e no qual

${ }^{38}$ Quanto a esse tema em específico: DESBONNETS, Théophile. Da intuição à instituição. Petrópolis: Vozes; Cefepal, 1987; e de FLOOD, David. Frei Francisco e o movimento franciscano. Petrópolis: Vozes; Cefepal, 1986.

39 AGAMBEN, 2015, p. 88.

40 É proverbial a resistência de Francisco a qualquer possível interpretação da Regra. Esta, como o evangelho, deveria ser vivida, não comentada. Sine glossa é um mote do movimento franciscano, a tal ponto que até hoje a tradição franciscana se recusa a fazer interpretações da Regra, preferindo as exposições. O alcance disso para pensar a política contemporânea não passou despercebido a Agamben, mas foi pouco aprofundado. Por exemplo, falta uma análise consistente do Testamento de Francisco em que a proibição de glosar a Regra aparece com uma força quase jurídica, o que não deixa de constituir um interessante paradoxo.

41 HEGEL, 1977. 
há uma vida nua que é excluída da política, para o vivente, no qual vida animal, nua, e vida política coincidem e onde essa vida que coincide é sua própria forma. Essa é a tarefa de pensar da modernidade à política contemporânea um dispositivo que se radicaliza e a possibilidade de torná-lo inoperante.

Agamben repete um procedimento que já se encontra em Hegel, tanto nos textos da juventude quanto em sua obra madura, que é considerar a íntima solidariedade de origem entre os conceitos teológicos e os do direito. A arqueologia da antropogênese, o caminho feito ao contrário, do homem contemporâneo à origem de sua conformação histórica, não pode ser feita sem reconhecer essa íntima solidariedade.

Reconhecemos, não obstante, que houve um processo no Ocidente, acentuadamente a partir do século XVIII, que resultou em verdadeira "guinada antropológica" que operou um deslocamento nas problemáticas da filosofia. Mas não nos basta ficar apenas nisso. Não se trata de um olhar para a antropologia, na medida em que usamos os conceitos da teologia e da filosofia para perguntar "o que é o homem?": suas preocupações, suas necessidades e mesmo sua relação com o infinito. A pergunta não é antropológica, mas antropogenética. Quase kantianamente, perguntamos com Agamben quais são as condições teóricas de possibilidades para que emirja o conceito "homem". Perguntamos ainda, e junto com Agamben, quais são as práticas, políticas, jurídicas e religiosas, que permitem que apareça esse homem contemporâneo, esse sujeito biopolítico no qual a vida mesma se encontra cindida.

Segundo Pannenberg, o sistema de Hegel foi o último que tentou "fundamentar a consciência pública da cultura em Deus em vez de no ser humano"43. Isso não significa que Hegel não tenha conhecido uma problemática antropológica, aliás, tal problemática é uma reivindicação da esquerda hegeliana. Mas no sistema do idealismo absoluto encontramos uma síntese de conceitos fundamentais da história da teologia. Agamben parece reconhecer nos Escritos da Juventude até a Fenomenologia os conceitos que elaboram um caminho pelo qual o homem aparece como um problema.

Os termos propostos por Agamben desde Hegel, mas também desde Foucault, Heidegger, Aristóteles, passando por boa parte do pensamento ocidental, não podem ser tomados apenas como categorias intelectuais. São, acima de tudo, experimentum, um expôr-se, em que também o filósofo se põe na esfera pública quando assume a tarefa do pensamento, tarefa compartilhada, comunidade.

Reconhecer essa interdependência originária dos conceitos que conforma o nosso modo de vida ocidental, que sustentam o paradigma biopolítico que tornam a vida manipulável, matável, violentável, é o primeiro passo para a sua articulação. E dentre todas as matrizes possíveis de pensamento que nos são oferecidas hoje, é apenas um processo arqueológico que se dá contemporaneamente na atividade filosófica e teológica que chegamos à compreensão da potência destituinte. O teólogo e o filóso-

\footnotetext{
${ }^{42}$ PANNENBERG, W. Filosofia e Teologia: Tensões e convergências de uma busca comum. São Paulo: Paulinas, 2008. p. 269.

43 PANNENBERG, 2008, p. 270.
} 
fo como destituidores: tornam inoperante a lei do pensamento que subjuga por meio do pensamento da lei que liberta para uma nova práxis.

\section{Referências}

AGAMBEN, Giorgio. A linguagem e a morte: Um seminário sobre o lugar da negatividade. Belo horizonte: UFMG, 2006. . Altíssima pobreza: Regras monásticas e forma de vida [Homo Sacer, IV, 1]. São Paulo: Boitempo, 2014. . A potência do pensamento: Ensaios e conferências. Belo Horizonte: Autêntica, 2017a. . Homo Sacer: O poder soberano e a vida nua, I. Belo Horizonte: UFMG, 2010. . Meios sem fim: Notas sobre a política. Belo Horizonte: Autêntica, 2015. . O que é um dispositivo? Outra travessia, Florianópolis: UFSC, n. 5, 2005. Disponível em: $<$ https://periodicos.ufsc.br/index.php/Outra/article/view/12576/11743>. Acesso em: 01 mar. 2018. O reino e a glória: Uma genealogia teológica da economia e do governo [Homo Sacer, II, 2]. São Paulo: Boitempo, 2011a. . O uso dos corpos: Homo sacer IV, 2. São Paulo: Boitempo, $2017 \mathrm{~b}$.

CASTRO, Edgardo. Introdução a Giorgio Agamben: Uma arqueologia da potência. Belo Horizonte: Autêntica, 2012.

DESBONNETS, Théophile. Da intuição à instituição. Petrópolis: Vozes; Cefepal, 1987.

FLOOD, David. Frei Francisco e o movimento franciscano. Petrópolis: Vozes; Cefepal, 1986. FONTES FRANCISCANAS. Celso Márcio Teixeira et al. (Orgs.). Petrópolis: Vozes, 2004.

HEGEL, Georg Wilhelm Friedrich. Fenomenologia do Espírito. Petrópolis: Vozes; Bragança Paulista: Editora Universitária São Francisco, 2008.

Hegels theologische Jungendschriften. Tübingen: Verlag, 1907.

Scritti teologici giovanili. Napoli: Guida Editori, 1977.

HYPPOLITE, Jean. Introdução à filosofia da história de Hegel. Rio de Janeiro: Elfos; Lisboa: Edições 70, 1995.

PANNENBERG, Wolfhart. Filosofia e teologia: Tensões e convergências de uma busca comum. São Paulo: Paulinas, 2008. 